proposed by Whitby et al. ${ }^{1}$ Discussions should take place between geographically related laboratories. These discussions should ensure that pathology services which are defined as non-core are provided in such a way as to maximise the use of local resources and to provide a professionally acceptable arrangement.

MJ GALLOWAY Department of Haematology, General Hospital, Co Durham DL14 6AD

1 Whitby LG, Bird CC, Collee JG, et al. Conequences of the provision of laboratory services for the National Health Service by commercial firms: a view from the University sector. J Clin Pathol 1990;43:441-4.

2 Shanks JM. Consequences of the provision of laboratory services for the National Health Service by commercial firms: a view from the private sector. J Clin Pathol 1990;43:525-6.

3 Galloway $M J$, Thompson RJ. On a business path. Health Services Journal 1990;100:672.

\section{Examination of faeces for bacterial pathogens}

The ACP Broadsheet No 124 is a valuable summary of the subject, ${ }^{1}$ and I am particularly delighted to see a reference to Kohn's two tube media which have been used in this laboratory for many years with great success and economy in time and, if properly used, materials. It is sad that this medium does not appear in a number of British textbooks and that one major British manufacturer has stopped supplying it. This is a retrograde step.

There is only one thing that concerns me and that is the inclusion of shigellas in the blanket recommendation (which otherwise is unexceptionable) that slide agglutination results should be confirmed by performing tube agglutinations. The late Patricia Carpenter maintained vigorously that it was not necessary to confirm slide agglutinations with shigellas by tube agglutinations. It may be argued that there are rare situations, such as with very uncommon Shigella boydii serotypes, when one might want to confirm the finding, and also it is wisely remarked in a recent edition of a standard British textbook that if there is doubt about a slide agglutination with Shigella, a confirmatory tube agglutination test should be performed. Both these latter points are, I am sure, valid, but a blanket recommendation that all Shigella slide agglutination results should be confirmed by performing tube agglutinations would, I think, surprise many workers, and it would be interesting to see if my views accord with those of others.

1 Pedler SJ, Orr KE. ACP Broadsheet 124: Examination of faeces for bacterial pathogens. J Clin Pathol 1990;43:410-5.

\section{BOOK REVIEWS}

\section{Some new titles}

The receipt of books is acknowledged, and this listing must be regarded as sufficient return for the courtesy of the sender. Books that appear to be of particular interest will be reviewed as space permits.

Photosensitizing Compounds: their Chemistry, Biology and Clinical Use. Ciba Foundation Symposium 146. (Pp 241; $£ 32.50$.) John Wiley. 1989. ISBN 0471 923087 .

Life Experiences, Development and Childhood Psychopathology. IM Goodyear. Wiley Series on Studies in Child Psychiatry. (Pp 292; 39.) John Wiley. 1990. ISBN 0-471-91602-1.

Diseases of the Liver and Bile Ducts. Based on Proceedings of 54th Annual Anatomic Pathology Slide Seminar of the American Society of Clinical Pathologist. J Ludwig, KG Ishak, DH Dail. (Pp 143; paperback \$48.) Raven Press. 1990. ISBN 0-89189-294-X.

Lung Cancer. Vol II. The Evolution of Concepts. Ed JG Gruhn, ST Rosen. (Pp 191; 55.) WW Norton \& Company Ltd 1989 ISBN 0938607170

I was delighted to receive this book to review as I had previously discovered and bought volume I. This I had thoroughly enjoyed and can recommend to any pathologist interested in lung cancer. Volume $I$ is almost entirely devoted to the pathological aspects of lung cancer; volume II only partly so. It is difficult to see why the subject matter has been separated into two volumes, for each is quite slim and together they would have made a text book of no more than 450 pages.

The book's subtitle (The Evolution of Concepts) is a somewhat obscure way of saying that they deal with a historical survey of lung cancer, from its very beginnings to the present day. If you find history dull, these books are not for you, but I find it difficult to envisage how anyone could take an interest in the subject of lung cancer without knowing how our present day concepts have evolved. These books present a very scholarly historical survey of the subject and make fascinating reading. Illustrations include some interesting portraits of early workers, reproductions of original papers, and some of the early electron micrographs. I thoroughly recommend both volumes to anyone interested in lung cancer and believe that they represent important reading for any aspiring authors in this field. Volume I contains chapters on the history of lung cancer histopathology, selected histopathological studies, precursor lesions, the production of hormones by lung tumours, the neuroendocrine lung, pulmonary cytopathology, and a historical perspective of our understanding of the aetiology and development of lung cancer. Volume II contains such subjects as tumour registries, the development of the bronchoscope, a history of the roentgenology of lung cancer, radiotherapy from Roentgen to the present, historical facets of thoracic surgery, pulmonary function studies and chemotherapy. The final two chapters, entitled "Oncogenes" and "The biology of lung cancer," are more likely to appeal to pathologists. Both volumes contain material of interest to the pathologist but this is particularly true of volume I.

B CORRIN

Biopsy Pathology of the Pulmonary

Vasculature. CA Wagenvoort, WJ Mooi. Biopsy Pathology Series 13. (Pp 362; $£ 59.50$.) Chapman and Hall Medical. 1989. ISSN 0412-27940-1.

Professor Wagenvoort and Dr Mooi have devoted their professional lives to the study of the histopathology of the pulmonary circulation. This splendid book represents a distillation of their researches. Open lung biopsy may be a rarity in some centres and when such a specimen arrives in the laboratory it is likely to cause difficulty. This volume provides ready help in such cases. There are very clear chapters dealing with how such material is to be obtained and processed. A straightforward description of the microanatomy of the normal pulmonary circulation precedes a series of exhaustive and well illustrated chapters on the pathology of the pulmonary vasculature in a comprehensive variety of congenital and acquired cardiopulmonary disorders. The sections on plexogenic arteriopathy and on the corrective operability of congenital heart disease, the latter a special interest of Wagenvoort's, are particularly good. Of greater value to the general histopathologist perhaps are the accounts of vasculopathies in primary lung disease and lung vessels in neoplastic disorders. There are well chosen lists of references at the end of each chapter, though it is disappointing that the work of Fernie and Lamb on the vexed question of measurement of medial hypertrophy and arterial contracture is not cited; only their paper on the effect of age and smoking on the pulmonary arterial intima receives mention. This book is well written and indexed. It is reasonably priced and should find a place in every diagnostic histopathology laboratory and hospital library.

MS DUNNILI

Diagnostic Neuropathology. Vol II. Ed JH Garcia, J Escalona-Zapata, U Sandbank, J Cervos-Navarro. (Pp 296; DM 160.) Springer. 1990. ISBN 3-540-50197-5.

This book is concerned with the study of biopsy material derived from central nervous system, peripheral nerve, and muscle for the purpose of diagnosis. It describes how tissue can best be handled and what disease processes can be correctly diagnosed using established techniques. It is intended to be of service to neurologists, neuroradiologists, neurosurgeons and pathologists.

There are four sections and two of them, concerning nerve biopsy and muscle biopsy, are straightforward and well illustrated accounts of well defined subjects. "Brain biopsy" is more difficult and controversial, embracing a varied assortment of neuropathological processes including neurodegenerative diseases of childhood, dementias of adult and late adult life, encephalitis, and so on. The authors wisely point out that other methods may be used in preference to brain 